\title{
Dlx5 and Dlx6 Regulate the Development of Parvalbumin-Expressing Cortical Interneurons
}

\author{
Yanling Wang, ${ }^{1 \star}$ Catherine A. Dye, ${ }^{1,2 \star}$ Vikaas Sohal, ${ }^{7}$ Jason E. Long, ${ }^{1,3}$ Rosanne C. Estrada, ${ }^{4}$ Tomas Roztocil, ${ }^{5}$ \\ Thomas Lufkin, ${ }^{6}$ Karl Deisseroth, ${ }^{7}$ Scott C. Baraban, ${ }^{4}$ and John L. R. Rubenstein ${ }^{1}$ \\ ${ }^{1}$ Department of Psychiatry, Nina Ireland Laboratory of Developmental Neurobiology, University of California, San Francisco, San Francisco, California \\ 94158, ${ }^{2}$ Department of Psychology, University of California, Riverside, Riverside, California 92521, ${ }^{3}$ Genentech Corporation, South San Francisco, California \\ 94080, ${ }^{4}$ Epilepsy Research Laboratory, Department of Neurological Surgery, University of California, San Francisco, San Francisco, California 94143, \\ ${ }^{5}$ Merck Serono, CH-1211 Geneva, Switzerland, ${ }^{6}$ Genome Institute of Singapore, Singapore 138672, and 7Departments of Psychiatry and Bioengineering, \\ Stanford University, Stanford, California 94305
}

Dlx 5 and Dlx6 homeobox genes are expressed in developing and mature cortical interneurons. Simultaneous deletion of Dlx 5 and 6 results in exencephaly of the anterior brain; despite this defect, prenatal basal ganglia differentiation appeared largely intact, while tangential migration of $L h x 6^{+}$and $M a f b{ }^{+}$interneurons to the cortex was reduced and disordered. The migration deficits were associated with reduced CXCR4 expression. Transplantation of mutant immature interneurons into a wild-type brain demonstrated that loss of either $D l x 5$ or $D l x 5 \& 6$ preferentially reduced the number of mature parvalbumin ${ }^{+}$interneurons; those parvalbumin ${ }^{+}$interneurons that were present had increased dendritic branching. $D l \times 5 / 6^{+1-}$ mice, which appear normal histologically, show spontaneous electrographic seizures and reduced power of gamma oscillations. Thus, Dlx $5 \& 6$ appeared to be required for development and function of somal innervating (parvalbumin ${ }^{+}$) neocortical interneurons. This contrasts with $D l x 1$, whose function is required for dendrite innervating (calretinin $^{+}$, somatostatin ${ }^{+}$, and neuropeptide $\mathrm{Y}^{+}$) interneurons (Cobos et al., 2005).

\section{Introduction}

Most rodent cortical interneurons are derived from progenitor domains in the prenatal subcortical telencephalon (subpallium) (Marin et al., 2003; Flames and Marin, 2005). The subpallium consists of four major subdivisions that have distinct molecular and morphological features: the lateral ganglionic eminence (LGE), medial ganglionic eminence (MGE), septum (SE), and preoptic area (POA). Moreover, caudal ganglionic eminence (CGE) exists as a caudal fusion of the MGE and LGE with distinct molecular domains that resemble caudal extensions of the MGE and LGE (Long et al., 2007).

The MGE is the source of the majority of interneurons that express parvalbumin (PV) and somatostatin (SST). On the other hand, there are at least two types of calretinin ${ }^{+}$and neuropeptide

\footnotetext{
Received Dec. 2, 2009; revised,; accepted Dec. 28, 2009

This work was supported as follows: to J.L.R.R. from Nina Ireland, the Larry L. Hillblom Foundation, National Institute of Mental Health (NIMH) Grants R01 and R37 MH49428-01, and K05 MH065670; to Y.W. from Citizens United for Research in Epilepsy Rhode Island Award from the Epilepsy Foundation; to C.A.D. from National Alliance for Research on Schizophrenia and Depression; to V.S. from a T32 postdoctoral training fellowship from NIMH; to K.D. from Stanford University, BioX/Bioengineering, NIMH, National Institute on Drug Abuse, National Science Foundation, California Institute of Regenerative Medicine, Howard Hughes Medical Institute, and the McKnight, Coulter, Kinetics, and Keck Foundations; and to S.C.B. from National Institutes of Health Grant 5R01 NS048528. The authors contributed to the figures as follows: Figs.1, 4:Y.W., C.A.D., J.E.L;Figs. 2, 3, 5-7:Y.W.; Fig.8:Y.W., V.S., S.C.B., R.C.E.; supplemental Fig.1:Y.W., C.A.D.; supplemental Figs 2, 3, 7: C.D., T.R., J.E.L.; supplemental Figs. 4-6, 8-11: Y.W. *Y.W. and C.A.D. are co-first authors.

Correspondence should be addressed to either Yangling Wang or John L. R. Rubenstein, Department of Psychiatry, Nina Ireland Laboratory of Developmental Neurobiology, University of California, San Francisco, 1550 4th Street, San Francisco, CA 04158. E-mail: Yanling.wang@ucsf.edu or john.rubenstein@ucsf.edu.

DOI:10.1523/JNEUROSCI.5963-09.2010

Copyright $\odot 2010$ the authors $\quad 0270-6474 / 10 / 305334-12 \$ 15.00 / 0$
}

$\mathrm{Y}(\mathrm{NPY})^{+}$interneurons: those expressing somatostatin are thought to derive from the MGE, and those that do not express somatostatin are thought to mainly derive from the CGE (Sussel et al., 1999; Pleasure et al., 2000; Xu et al., 2004; Butt et al., 2005; Wonders and Anderson, 2006; Flames et al., 2007; Fogarty et al., 2007; Xu et al., 2008). Flames et al. (2007) found that dorsal and ventral subdivisions of the MGE produce different ratios of cortical interneuron subtypes; dorsal regions preferentially produce $\mathrm{SST}^{+}$, whereas ventral regions preferentially produce $\mathrm{PV}^{+}$. They correlated this with molecular features of the MGE to provide insights for a transcription factor code in generating distinct neocortical interneuron subtypes.

Information about the transcriptional control of interneuron development has come from the analysis of Arx, Dlx1\&2, Dlx1, Lhx6, and Nkx2.1 mutants. Most interneurons require Dlx1\&2 (Anderson et al., 1997a,b; Yun et al., 2002; Cobos et al., 2006; Long et al., 2007, 2009a,b). Dlx1/2 ${ }^{-1-}$ mutants have a severe deficit in the survival and migration of immature cortical and hippocampal interneurons. While $D l x 1$ is widely expressed in immature interneurons, its postnatal expression is only detectable in subsets of $\mathrm{SST}^{+}, \mathrm{NPY}^{+}$, and most $\mathrm{CR}^{+}$interneurons, where it is required for their survival (Cobos et al., 2005, 2006, 2007). Virtually all $\mathrm{PV}^{+}$and SST ${ }^{+}$interneurons, and subsets of $\mathrm{CR}^{+}$and $\mathrm{NPY}^{+}$interneurons, depend on expression of $\mathrm{Nk} \times 2.1$ and Lhx6 (Sussel et al., 1999; Pleasure et al., 2000; Liodis et al., 2007; Du et al., 2008; Zhao et al., 2008). Dlx1/2 ${ }^{-1-}$ and $\operatorname{Lh} \times 6^{-1-}$ have reduced Arx expression. (Cobos et al., 2006; Zhao et al., 2008). Arx mutants have reduced interneuron migration (Kitamura et al., 2002; Colombo et al., 2007; Colasante et al., 

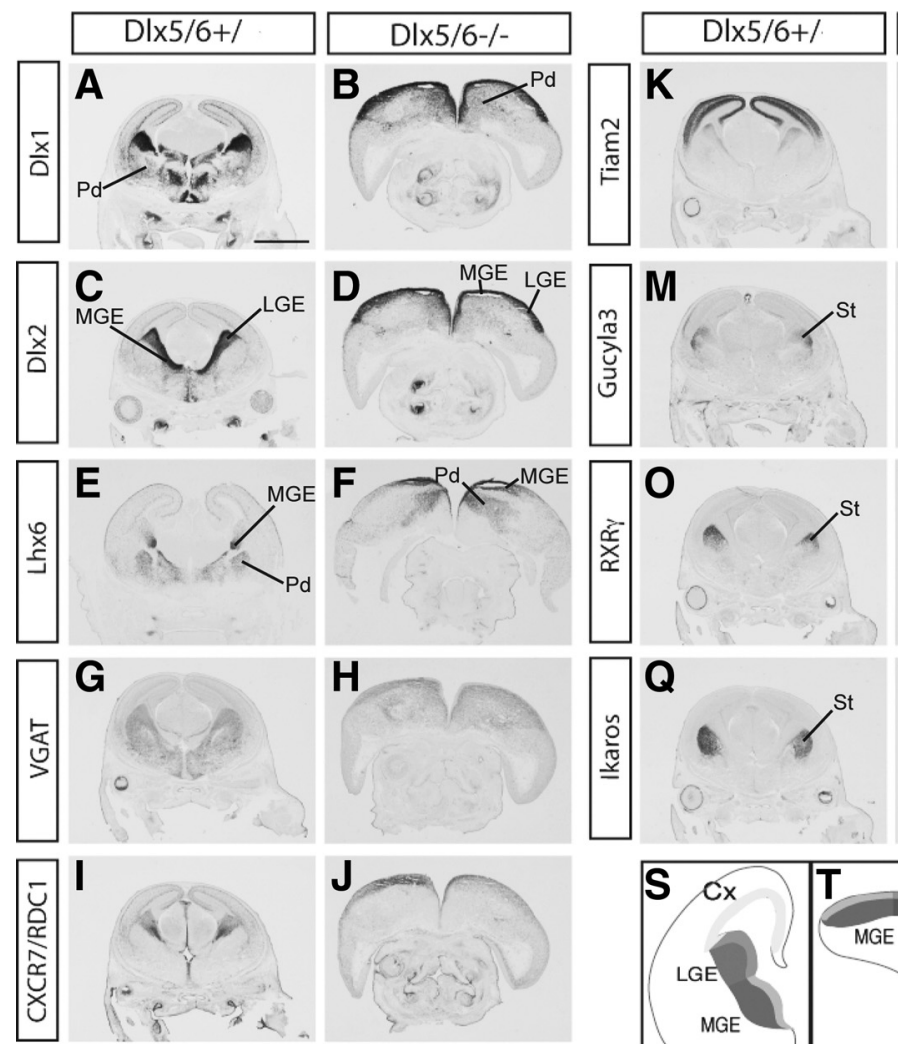
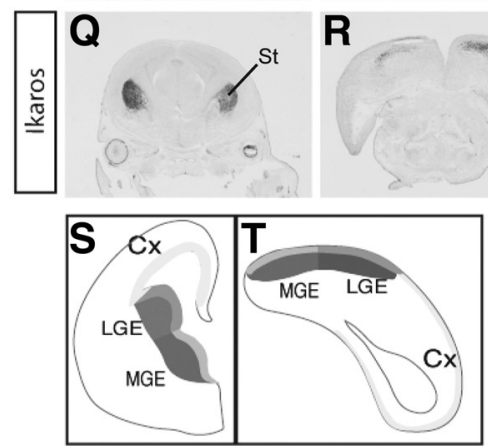

Figure 1. A-T, Preservation of telencephalic regional patterning and features of subpallial differentiation in E15.5 D/ $\times 5 / 6^{-/-}$ mutants. The $D / \times 5 / 6^{-1-}$ mutants are exencephalic; a schematic representation of $D / x 5 / 6^{+/}(\boldsymbol{S})$ and $D / x 5 / 6^{-1-}(\boldsymbol{T})$ is presented to help the reader orient the regions of the exencephalic telencephalon. Coronal sections from $D / x 5 / 6^{+/}$and $D / \times 5 / 6^{-1-}$ were labeled by in situ hybridization with markers of LGE and MGE progenitor and mantle zones; the DIx5/6 ${ }^{-1-}$ mutants do not show major gene expression defects, although the morphologies of the telencephalic regions are abnormal $(\boldsymbol{A}-\boldsymbol{R})$. Cx, Cortex; $\mathrm{Pd}$, pallidum (including globus pallidus); St, striatum. Scale bar, $1.5 \mathrm{~mm}$.

2008; Fulp et al., 2008). While the function of $D l \times 1$ and $D l \times 2$ in telencephalic development has been well established, the function of $D l x 5$ and $D l x 6$ is just beginning to be elucidated. $D l x 5$ is known to promote differentiation of olfactory bulb interneurons (Levi et al., 2003; Long et al., 2003); no information is available on Dlx6 function. Because Dlxl\& 2 are required to induce expression of Dlx $\& 6$ in the LGE and MGE subventricular zones (Anderson et al., 1997b; Zerucha et al., 2000; Long et al., 2007), it is unclear to what extent the $D l \times 1 / 2^{-1-}$ phenotype reflects loss of $D l x 1 \& 2$ or $D l x 1,2,5 \& 6$ function. Here we present the first evidence that $D l x 5$ and $D l x 5 \& 6$ are required for development and function of neocortical $\mathrm{PV}^{+}$interneurons.

\section{Materials and Methods}

Animals and tissue preparation. Dl $x 5$ and Dlx 266 loss of function mutant mice were previously described (Depew et al., 1999; Robledo et al., 2002). Lhx6-GFP and Dlx5-GFP BAC transgenic mouse lines were obtained from GENSAT (http://www.gensat.org/index.html). Dlx5/6i-Cre mice were also previously described (Kohwi et al., 2007). For staging of embryos, midday of the vaginal plug was calculated as embryonic day 0.5 (E0.5). Mouse colonies were maintained in accordance with the protocols approved by the Committee on Animal Research at University of California, San Francisco, San Francisco, CA. Embryos were anesthetized by cooling, dissected, and immersion fixed in $4 \%$ paraformaldehyde (PFA) in PBS for $4-12 \mathrm{~h}$. Samples were then cryoprotected in $30 \%$ sucrose and cut $20 \mu \mathrm{m}$ using a cryostat.

In situ hybridization. In situ hybridization experiments were performed using digoxigenin riboprobes on $20 \mu \mathrm{m}$ frozen sections as de-

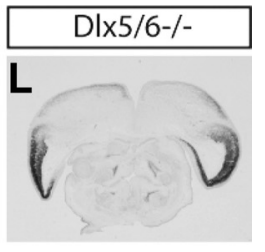

scribed previously. Briefly, slides were fixed in $4 \%$ PFA for $20 \mathrm{~min}$, treated with proteinase $\mathrm{K}$ $(1 \mu \mathrm{g} / \mathrm{ml}$ ) for $15 \mathrm{~min}$. Acetylation was performed using $0.25 \%$ acetic anhydride in $0.1 \mathrm{M}$ triethanolamine, $\mathrm{pH} 8.0$, for $10 \mathrm{~min}$, followed by three PBS washes. Slides were incubated with hybridization buffer for $2 \mathrm{~h}$ at RT, followed by overnight incubation with a digoxigenin-labeled probe at $72^{\circ} \mathrm{C}$. Three highstringency washes were performed with $0.2 \times$ SSC at $72^{\circ} \mathrm{C}$. Slides were then incubated with horseradish alkaline phosphatase-conjugated anti-digoxigenin and NBT (nitroblue tetrazolium)/BCIP (5-bromo-4-chloro-indolyl phosphate) for signal detection. The probes used and their sources were as follows: Cxcl12 (Samuel J. Pleasure, Scripps Research Institute, La Jolla, CA), Cxcr4 (Dan Littman, New York University, New York, NY), Cxcr7 (RDC1) (American Type Culture Collection MGC18378), Dlx1, Dlx2 (laboratory of J.L.R.R.), ErbB4 (Cary Lai, Scripps Research Institute, La Jolla, CA), Gad67 (Brian Condie, University of Georgia, Athens, GA), Gucyla3 (Imagen/Gene Cube), Ikaros (Katia Georgopolos, Massachusetts General Hospital, Charlestown, MA), Lhx6 (Vassilis Pachnis, National Institute for Medical Research, London, UK), Reelin (Tom Curran, Children's Hospital of Philadelphia, Philadelphia, PA), RXR $\gamma$ (Kenneth Campbell, University of Cincinnati School of Medicine, Cincinnati, OH), Somatostatin (Tom Lufkin, Mount Sinai School of Medicine, New York, NY), Tiam2 (GenBank accession no. BM228957), and VGAT (GenBank accession no. NM_009508.2).

Immunohistochemistry. Animals were deeply anesthetized (P60) and perfused intracardially with $4 \%$ paraformaldehyde in PBS $(0.1 \mathrm{M}, \mathrm{pH}$

7.4). The brains were removed and postfixed overnight in the same fixative and cryoprotected by immersion in $30 \%$ sucrose. Free-floating cryostat sections $(40 \mu \mathrm{m})$ were processed using standard procedures. Primary antibody dilutions used were as follows: rabbit anti-calretinin (CR) (1:2000; Immunostar), anti-parvalbumin (1: 2000; Swant Swiss Antibodies); rat anti-somatostatin (1:200, Millipore Bioscience Research Reagents) or rabbit anti-NPY (1:2000, Immunostar), rabbit anti-GFP (1:2000, Moleular Probes), anti-phosphorylated histone H3 (1:200, Millipore). Secondary antibodies were as follows: Alexa 488 goat anti-rabbit, Alexa 488 goat anti-chicken, Alexa 594 goat anti-rat, Alexa 594 goat anti-rabbit. Immunoperoxidase staining was performed by using the ABC elite or M.O.M. kit (Vector Laboratories).

MGE dissections. Exencephalic telencephali of Dlx5/6 ${ }^{-1-}$ mutants possess a characteristic appearance; the pallium is located laterally, whereas the subpallium is located in medially (supplemental Fig. $1 A-D$, available at www.jneurosci.org as supplemental material). To gain a better view of GFP expression in $D l \times 5 / 6^{-1-}$ brains, we removed the pallium from the subpallium and positioned (flipped) the subpallium so that its pial sidefaced upward (supplemental Fig. $1 G$, available at www.jneurosci. org as supplemental material). The area with the strongest GFP intensity in Dl $\times 5 / 6^{-1-}$ mutants was located slightly off of the medial-most side of the telencephalon, roughly halfway along the rostral-caudal axis, and deep to the ventricular surface. This intensely positive GFP region was present in all genotypes studied: $D l \times 5^{+/+}, D l \times 5^{-1-}, D l \times 5 / 6^{+/+}$, and Dl $\times 5 / 6^{-1-}$ and was designated the MGE mantle zone/ventral subpallium (supplemental Fig. 1 E, F, available at www.jneurosci.org as supplemental material). For transplantation, we used the ventricular/subventricular zone (VZ/SVZ) region just superficial to the intensely GFP-positive region. To dissect the VZ/SVZ region of Dlx5/6 ${ }^{-1-} \mathrm{MGE}$, four cuts were made at the edges of the intensely GFP-positive region; two cuts were 
made along medial-lateral axis at their anterior and posterior limits, then two were made along the rostral-caudal axis at their lateral and medial limits (supplemental Fig. $1 G$, available at www.jneurosci.org as supplemental material). The excised tissue block corresponds to the MGE; it was then rotated $90^{\circ}$, placing it on one of its cutting surfaces. We then made an incision that separated the VZ/SVZ from the mantle zone. The surface $\mathrm{VZ/SVZ}$ region (dotted line area in supplemental Fig. $1 E, F$, available at www. jneurosci.org as supplemental material) was removed and processed for the transplantation and cell culture.

Transplantation. Cell transplantations of interneuron precursors from $D l x 5^{+/+}, D l x 5^{-/-}$, $D l \times 5 / 6^{+/+}$, and $D l \times 5 / 6^{-1-}$ donors into WT neonates [postnatal day $0(\mathrm{P} 0)$ ] were performed as described previously (Cobos et al., 2005). Embryos carrying Lhx6-GFP BAC transgene were dissected at E13.5. VZ/SVZ regions of medial ganglionic eminences were dissected from each embryo in HBSS (Invitrogen). Explants were then washed with $200 \mu \mathrm{l}$ of HBSS medium containing $50 \mu \mathrm{g} / \mathrm{ml}$ DNase I (Roche) and mechanically dissociated. Dissociated cells were concentrated by centrifugation $(3 \mathrm{~min}, 800 \times g$ ) and resuspended in $2 \mu \mathrm{l}$ of HBSS. Cell suspensions were loaded into glass micropipettes $(\sim 50$ $\mu \mathrm{m}$ diameter) that were prefilled with mineral oil. Micropipettes were connected to a microdispenser (Drummond) with direct readout for fractional microliters. Recipient pups (P0) were anesthetized on ice. A total of $5 \times 10^{5}$ cells per mouse in a $100-200 \mathrm{nl}$ of volume was injected into parietal cortex in a single point using a $45^{\circ}$ inclination angle. Grafted pups were returned to their mothers and analyzed after 2 months. The percentage of $\mathrm{GFP}^{+}$cells expressing CR, PV, SST or NPY in grafted animals was determined using a BX-60 microscope (Olympus) equipped with epifluorescence illumination. At least $100 \mathrm{GFP}^{+}$in cortex were analyzed per each marker in each animal.

Cell culture. Cultures of Dlx5/6 ${ }^{+/}$or ${ }^{-1-}$ MGE cells were established and maintained using previously described methods (Xu et al., 2004). Briefly, the MGE was identified by both morphological appearance and location of GFP fluorescence and dissected into cold Hank's Buffer. Tissue was cut into pieces and transferred into Neurobasal medium supplemented with B-27 before trypsinization. Trypsinization for $15^{\prime}$ at $0.05 \%$ plus $10 \mu \mathrm{g} / \mathrm{ml}$ DNase was performed at $37^{\circ} \mathrm{C}$, terminated by the addition of an excess of DMEM supplemented with Fetal Bovine Serum (FBS), and followed by two rounds of mechanical dissociation. The first used large bore Pasteur pipettes, the second used small bore pipettes. Cells were pelleted in between and following the second dissociation by centrifugation at $2000 \mathrm{rpm}, 4^{\circ} \mathrm{C}, 4 \mathrm{~min}$, and resuspended in cold DMEM/ FBS. Before plating, cells were strained and counted using a hemocytometer. $5000 \mathrm{MGE}$ cells were plated into one chamber $\left(0.4 \mathrm{~cm}^{2}\right)$ of a 16 chamber slide (LABTEK) that had been previously coated with laminin and poly-L-lysine ( $2 \mathrm{~d}$ prior) and seeded ( $1 \mathrm{~d}$ prior) with $\sim 1 \times 10^{5}$ cortical cells isolated from GFP-negative CD1 P0 or P1 neonates as described above. Cultures were grown at $37^{\circ} \mathrm{C}$ under $5-6 \% \mathrm{CO}_{2} .50 \%$ of the media was exchanged for NB/B-27 at $1 \mathrm{~d}$ postplating, $2 \mathrm{~d}$ postplating, and every other day following. At the termination point, cells were fixed in $4 \%$ Paraformaldehyde/PBS before GFP immunohistochemistry. GFP cells were counted by hand using a compound fluorescence microscope. The ratio of the numbers of GFP-positive cells/chamber at $5 \mathrm{~d}$ in vitro (DIV) and $10 \mathrm{DIV}$ or 5 DIV and 40 DIV is defined as percent survival.

Video-electroencephalography. For monitoring, surface head mount electroencephalography (EEG) hardware was purchased from Pinna-

\section{Dlx5/6+1+}
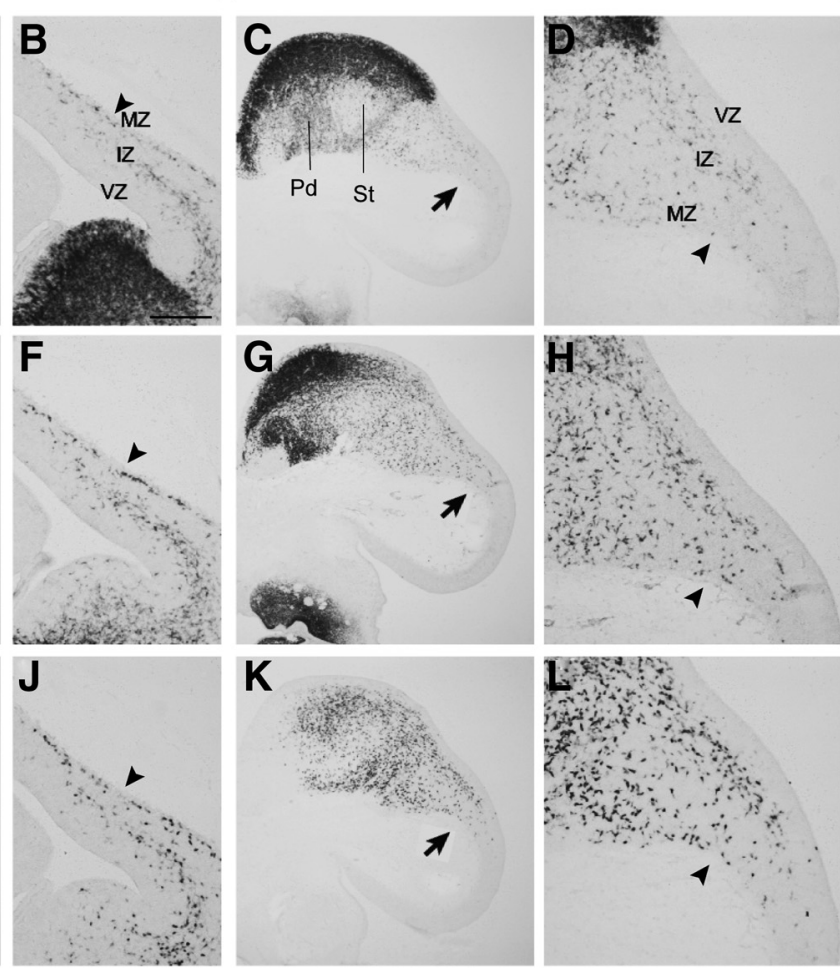

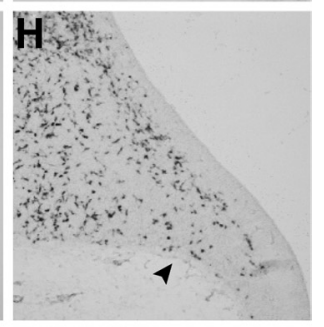

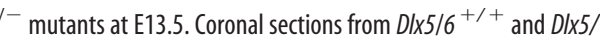
$6^{-I-}$ were labeled by in situ hybridization against DIx1 (A-D), Lhx6 $(\boldsymbol{E}-\boldsymbol{H})$ and Somatostatin $(\boldsymbol{I}-\boldsymbol{L})$. The arrows point to the leading migrating cells. Note superficial migratory stream (arrowheads) in $M Z$ is poorly formed in $D / \times 5 / 6^{-1-}$ mutants. Scale bars: (in $A) A, C, E, G, I, K, 300 \mu \mathrm{m}$; (in $B) B, D, F, H, J, L, 200 \mu \mathrm{m}$.

cle Technology. Mice were anesthetized and the skull surface was exposed with a single rostral/caudal incision. Head mounts were attached with four conductive stainless steel screws, which also acted as recording electrodes. Two wires were laid on top of the shoulder muscles for electromyographic recording. Dental cement was used to secure the head mount, and mice recovered for $4 \mathrm{~d}$ before recordings commenced. Recordings were sampled at $400 \mathrm{~Hz}$ and high-pass filtered at $1 \mathrm{~Hz}$ (EEG) and $10 \mathrm{~Hz}$ (EMG). Each mouse was monitored 3-12 h/d; up to 8 nonconsecutive days (alternating day and night recording sessions when possible). A total of $16,980 \mathrm{~min}(34 \mathrm{~d})$ of recording were obtained for $D l \times 5 / 6^{+/-}$mice and $9933 \mathrm{~min}(28 \mathrm{~d})$ for controls. Low-pass filtering was done at $40 \mathrm{~Hz}$ (EEG) and $100 \mathrm{~Hz}$ (EMG). Simultaneous video was obtained at two different angles using Microsoft LifeCam VX-3000 cameras linked via a USB-port to a PC-based computer running Active WebCam software. Seizure discharges were detected by SireniaScore software (Pinnacle Technology) and confirmed by off-line review by an investigator blind to the status of the animal.

Wavelet-based power measurements. We measured power in $60 \mathrm{~s}$ EEG recordings. We recorded EEG from two sites in each mouse, as described previously (Baraban et al., 2009). Recordings were chosen to occur during period of wakefulness and to be free of cortical spikes and electrographic seizures. For each $60 \mathrm{~s}$ recording, we computed the power as a function of frequency and time. Frequency varied between 4 and $200 \mathrm{~Hz}$, using $2 \mathrm{~Hz}$ increments. Time was measured by dividing each $60 \mathrm{~s}$ recording into $1 \mathrm{~s}$ epochs. To measure the power at frequency $f$ within each 1-s-long epoch, we first bandpass filtered the recording between $f \pm 2 \mathrm{~Hz}$, then convolved the filtered signal with a wavelet with frequency $f$, defined as follows: $W f t=e-t 243 f 2 e 2 \pi i f t$.

We used the squared amplitude of the result to measure the instantaneous power at that frequency. The power during a $60 \mathrm{~s}$ recording was the average of the power measured during each of the 1-s-long epochs within that recording. 


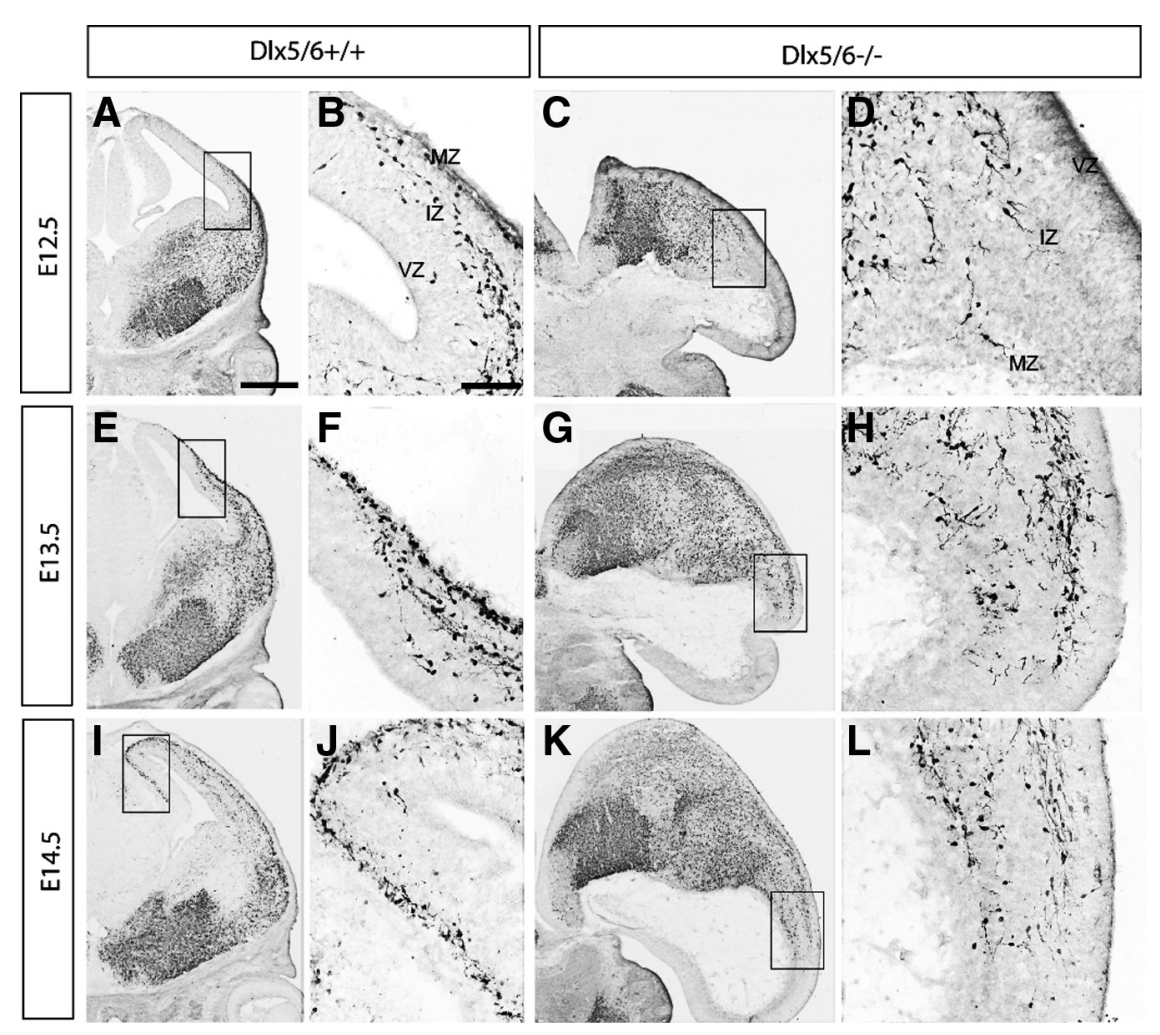

Figure 3. A-L, Reduced tangential migration and accumulation of Lhx6-GFP-positive cells in the SVZ of the $L G E$ of $D / \times 5 / 6^{-/-}$ mutants at E12.5, E13.5, and E14.5. Immunohistochemistry for GFP was performed on coronal sections from E12.5 (A-D), E13.5 $(\boldsymbol{E}-\boldsymbol{H})$, and $\mathrm{E} 14.5(\boldsymbol{I}-\boldsymbol{L}) \mathrm{D} \times 55 / 6^{+/+}$and $\mathrm{D} / \times 5 / 6^{-/-}$mutants. Boxed areas shown in high magnification are the migrating cells at the front of migration. D/x5/6 ${ }^{-1-}$ mutants show reduced tangential migration and an accumulation of Lhx6-GFP cells in the SVZ of the LGE. Scale bars: (in $A) A, C, E, G, I, K, 500 \mu \mathrm{m}$; (in $B) B, D, F, H, J, L, 200 \mu \mathrm{m}$.

Cell counting in histological sections. The number of interneurons expressing different genes (E16.5), the percentage of Dlx5-GFP ${ }^{+}$cells expressing DLX2 (E15.5) or standard interneuron markers (P60), were determined in the lateral cortex (E15.5 and E16.5) and somatosensory cortex (P60) respectively. Statistical analysis was performed using the Student's $t$ test or ANOVA analysis.

\section{Results}

\section{Exencephalic $D l x 5 / 6^{-1-}$ mutants have normal telencephalic patterning}

Previous reports demonstrated that simultaneous deletion of Dlx 5 and 6 results in exencephaly in the anterior brain, which is mainly due to distinctive craniofacial defects and the complete absence of calvaria. (Depew et al., 2002; Robledo et al., 2002). To evaluate regional patterning and differentiation within this dysmorphic forebrain, we used in situ hybridization on E15.5 coronal sections. As a visual aid, we show schematic representations of the pallial and subpallial domains of coronal sections of wild-type and $D l \times 5 / 6^{-1-}$ brains (Fig. $1 S, T$; supplemental Fig. 2, available at www.jneurosci.org as supplemental material). Dlx1 and Dlx2 are expressed in the subpallial VZ and SVZ (ventricular and subventricular zones), and in migratory interneurons on their path from the MGE and caudal LGE into the cortex (Fig. 1A,C); their expression appeared intact in the VZ and SVZ of the LGE and MGE (Fig. $1 B, D$ ), and in interneurons that are tangentially migration to the cortex (see Fig. 4 for higher magnification). Lhx6 labels the SVZ and the mantle region of the MGE, and a large fraction of tangentially migrating interneurons; this expression was largely preserved in the $D l \times 5 / 6^{-1-}$ mutants (Fig. 1E,F; supplemental
Fig. 3, available at www.jneurosci.org as supplemental material) (see Fig. 4 for higher magnification)

In Dl $\times 1 / 2^{-1-}$ mutants, Dlx5 and 6 expression are almost eliminated from the LGE and MGE (Anderson et al., 1997a); thus it is possible that a significant component of their phenotype results from the loss of $D l x 5$ and 6 expression. Thus, we assessed the expression of a subset of genes that are strongly downregulated in the LGE and MGE of $D l \times 1 / 2^{-/-}$mutants (VGAT, CXCR7, Tiam2, Gucy1a3, RXR $\gamma$, and Ikaros) (Long et al., 2007; Long et al., 2009a,b). However, in the Dlx5/6 ${ }^{-1-} \mathrm{mu}$ tants, expression of these genes was not grossly reduced (Fig. $1 G-R$ ), demonstrating that their transcription is strongly dependent on $D l x 1 \& 2$ or other downstream effectors.

\section{Interneuron migration is reduced in Dlx5/6 ${ }^{-/-}$mutants}

The majority of GABAergic interneurons of neocortex and hippocampus are generated from the ganglionic eminences and tangentially migrate to the developing cortex. Early-born populations of interneurons emerge from the MGE and invade the cortex by E13. To examine whether the $D l \times 5 / 6^{-1-}$ mutation affects early interneuron migration, we assessed expression of interneuron markers ( $D l x 1$, Lhx6, and somatostatin) by in situ hybridization. In $D l \times 5 / 6^{+/+}$embryos, superficial and deep migratory streams were present in the $M Z$ and intermediate zone (IZ)/SVZ, respectively, and the leading migrating cells (denoted by black arrows) in $\mathrm{MZ}$ already reached the dorsal cortex (Fig $2 A, E, I$ ). In $D l \times 5 / 6^{-1-}$ embryos, the leading migrating cells did not migrate as far into the dorsal neocortex as in wild-type controls (Fig $2 C, G, K$, black arrows); Although the deep migratory stream was maintained, the superficial migratory steam was poorly formed (Fig 2, compare $D, H, L$ arrowheads, $B, F, J$ arrowheads).

To follow the progression of this phenotype, we studied the interneuron distribution using a transgenic marker. We crossed a BAC transgene encoding the Lhx6 gene, which is driving expression of green fluorescent protein (GFP) (Cobos et al., 2006). GFP immunohistochemistry in $D l \times 5 / 6^{+/+}$and $D l \times 5 / 6^{-1-}$ telencephalons at E12.5, E13.5, and E14.5 revealed a progressive retardation in the migration of Lhx6-expressing interneurons, in both the deep and superficial migratory streams in $D l \times 5 / 6^{-1-}$ mutants (Fig. 3). We noticed that leading migrating cells in $D l \times 5 / 6^{-1-}$ mutants at E14.5 reached roughly halfway as far as that in Dlx5/ $6^{+/+}$controls. This evidence for a delay suggested that all $\operatorname{Lh} \times 6-$ $\mathrm{GFP}^{+}$interneurons (may include some interneurons that do not normally express $D l \times 5 / 6)$ were affected upon loss of $D l \times 5 / 6$ function. It should be noted that we cannot rule out that the excencephalic phenotype contributed in a nonautonomous manner to this phenotype. We also detected an accumulation of $\operatorname{Lh} x 6^{+}$interneurons in the SVZ of lateral ganglionic eminences (supplemental Fig. 4, available at www.jneurosci.org as supplemental material), suggesting reduced efficiency in the tangential migra- 
tion of interneurons in $\mathrm{Dl} \times 5 / 6^{-1-} \mathrm{mu}-$ tants. Overall, Dl $\times 5 / 6^{-1-}$ mutants demonstrated a slowing of migration rather than a block in migration, in contrast with the $D l \times 1 / 2^{-1-}$ mutants (Anderson et al., 1997b; Marin et al., 2000).

The exencephalic $D l \times 5 / 6^{-1-}$ brains underwent degeneration at late gestational stages; the oldest brains that we could reliably analyze were E16.5. At this stage, we assessed neocortical interneuron molecular properties and extent of their migration by performing in situ hybridization to detect Dlx1, Dlx2, GAD67, Lhx6, and MafB (Fig. 4A-L). We quantified the total number of cells expressing these genes within $125,000 \mu \mathrm{m}^{2}$ of the lateral cortex, and the number of positive cells in each of the cortical layers [VZ, SVZ, IZ, cortical plate (CP), MZ]. Our data showed that there was a general reduction of $D l x 1^{+}, D l x 2^{+}, G A D 67^{+}$, $L h x 6^{+}$cells in lateral cortex; the reduction was most severe in $\mathrm{MZ}$ and SVZ, however there was a preferential depletion of $\operatorname{Lhx} 6$ and $M a f B$ within the MZ (Fig. 4M). Furthermore, while the number of $\mathrm{MafB}^{+}$ cells was normal, their laminar distribution was greatly disturbed (Fig. $4 M$ ). Thus, the Dl $\times 5 / 6^{-1-}$ mutation appears to preferentially affect the $L h x 6^{+}$and $M a f B^{+}$migrating interneurons within the neocortex.

\section{Loss of CXCR4 expression in deep} migrating interneurons in the $D l x 5 / 6^{-/}$ - mutants

Toward elucidating the mechanism(s) underlying the reduced number of interneurons in the $D l \times 5 / 6^{-1-}$ cortex, we tested the expression of molecules that are implicated in regulating interneuron migration. To determine whether the exencephaly altered the properties of the meninges, we examined expression of the cytokine stromal-derived factor-1 (SDF1), which is known to regulate migration and laminar positioning of interneurons and Cajal Retzius cells (Stumm et al., 2003; Borrell and Marin, 2006; Li et al., 2008; Lopez-Bendito et al., 2008). Despite the gross malformation, SDF1 expression in the meninges was apparent; however, the cavity formed by the everted exencephalic cortex was filled with $S D F 1^{+}$ cells. (Fig. $5 B^{\prime}$, asterisk). SDF1 expression in the intermediate zone of ventrolateral cortex appeared normal (Fig. $\left.5 B, B^{\prime}\right)$.

Next we assessed the properties of the neocortical marginal zone, which contains Reelin-expressing Cajal Retzius cells that tangentially migrate over its surface from several sources (Bielle et al., 2005). Reelin expression has a prominent role in regulating the laminar position of cortical projection neurons and interneurons, although it is unclear whether the interneuron phenotypes are cell autonomous (Hevner et al., 2004; Hammond et al., 2006; Pla et al., 2006; Yabut et al., 2007). Reelin expression appeared roughly normal in the $D l \times 5 / 6^{-1-}$ mutants (Fig. $5 D, D^{\prime}$ ). Thus, the tangential migration of Reelin ${ }^{+}$cells to cover the cortex shows that the reduction of $D l x 1, D l x 2, L h x 6$, and GAD67 expression in the marginal zone is not due to a general disruption of migration in this layer.

Migrating interneurons express several known receptors that promote their migrations. First we examined expression of two
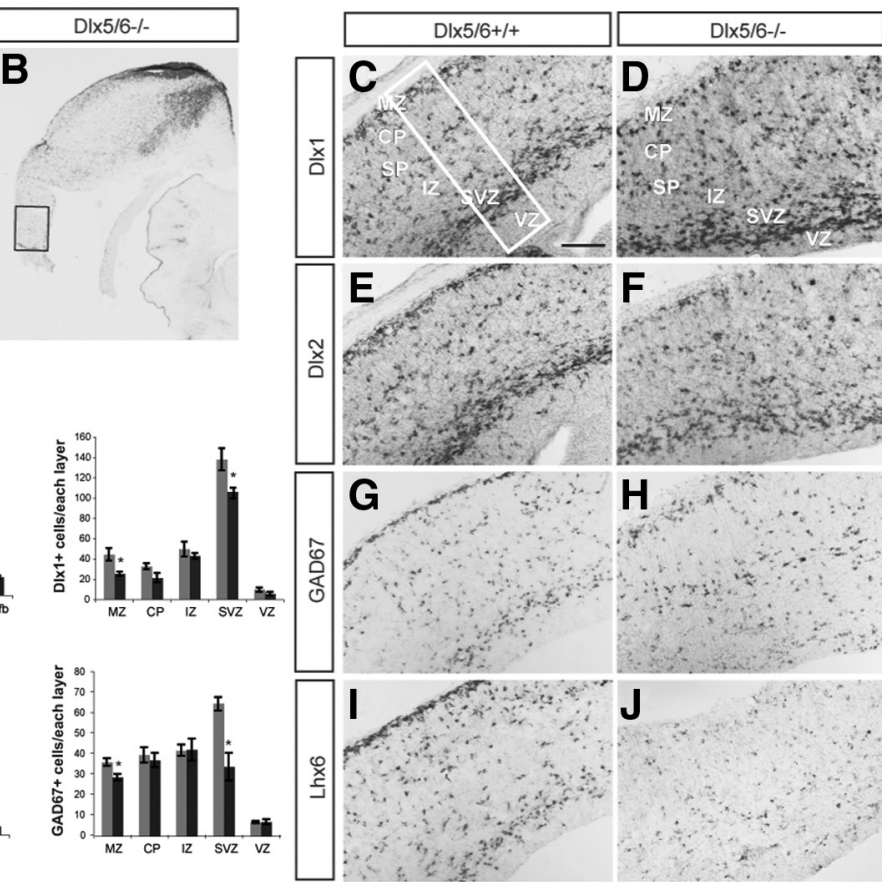

$\mathbf{J}$
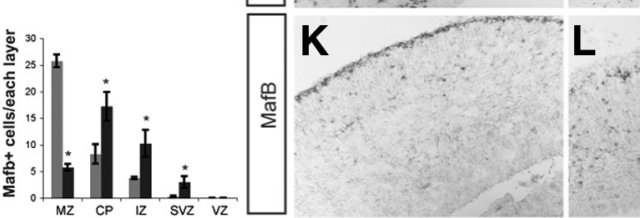

Figure 4. $A-M$, Reduced number of $D\left(x 1^{+}, D 1 \times 2^{+}, G A D 67^{+}\right.$, and $L h \times 6^{+}$cells in the lateral cortex of $D / x 5 / 6^{-1-}$ mutants atE16.5. in situ hybridization with probes for $L h \times 6(A, B, I, J), D|x 7(C, D), D| x 2(E, F), G A D 67(G, H)$, and $M a f B(K, L)$ was performed on coronal sections and $D / \times 5 / 6^{-1-}$ mutants. The boxes in $\boldsymbol{A}$ and $\boldsymbol{B}$ show the region that is shown at higher magnification in C-L. The box in $\boldsymbol{C}$ 列 eocortex and the number of positive cells in each of the cortical layers are presented $(M)$. The reduction is most severe in MZ and SVZ

receptors for SDF1: CXCR4 and CXCR7 (RDC, CMKOR1). $C X C R 4$ regulates laminar positioning of interneurons (Stumm et al., 2003; Li et al., 2008; Liapi et al., 2008; Lopez-Bendito et al., 2008; Tiveron and Cremer, 2008); the function of CXCR7 has not been established, but its expression is reduced in $D l \times 1 / 2^{-/-} \mathrm{mu}-$ tants (Long et al., 2009a,b). In Dlx5/6 ${ }^{-1-}$ mutants, although CXCR4 expression appeared intact in Cajal Retzius cells and in the striatum, its expression was not detectable in interneurons tangentially migrating in the cortex (Fig. $5 I^{\prime}, J^{\prime}$, arrows). In contrast, CXCR7 expression in migrating interneurons appeared normal (Fig. $5 E^{\prime}, F^{\prime}$, arrows).

Finally, we examined expression of $\operatorname{ErbB} 4$, a receptor for neuregulin, which also promotes interneuron migration (Flames and Marin, 2005). The expression of ErbB4 was maintained in the MGE and LGE, and in deep migrating interneurons in $D l \times 5 / 6^{-1-}$ mutants (Fig. 5 $G^{\prime}, H^{\prime}$ ). Furthermore, the expression of two ErbB4 ligands, neuregulin1 (NRG-1) and sensory and motor neuronderived factor (SMDF; a form of neuregulin 1) was intact in Dlx5/ $6^{-1-}$ mutants (supplemental Fig. 5, available at www.jneurosci. org as supplemental material). Thus, the reduction in CXCR4 expression may contribute to the interneuron migration deficit of Dlx5/6 ${ }^{-1-}$ mutants.

\section{Dlx5/6 regulate interneuron specification in cell-autonomous manner}

While loss of CXCR4 expression in migrating interneurons may contribute to the reduced numbers of tangentially migrating in- 


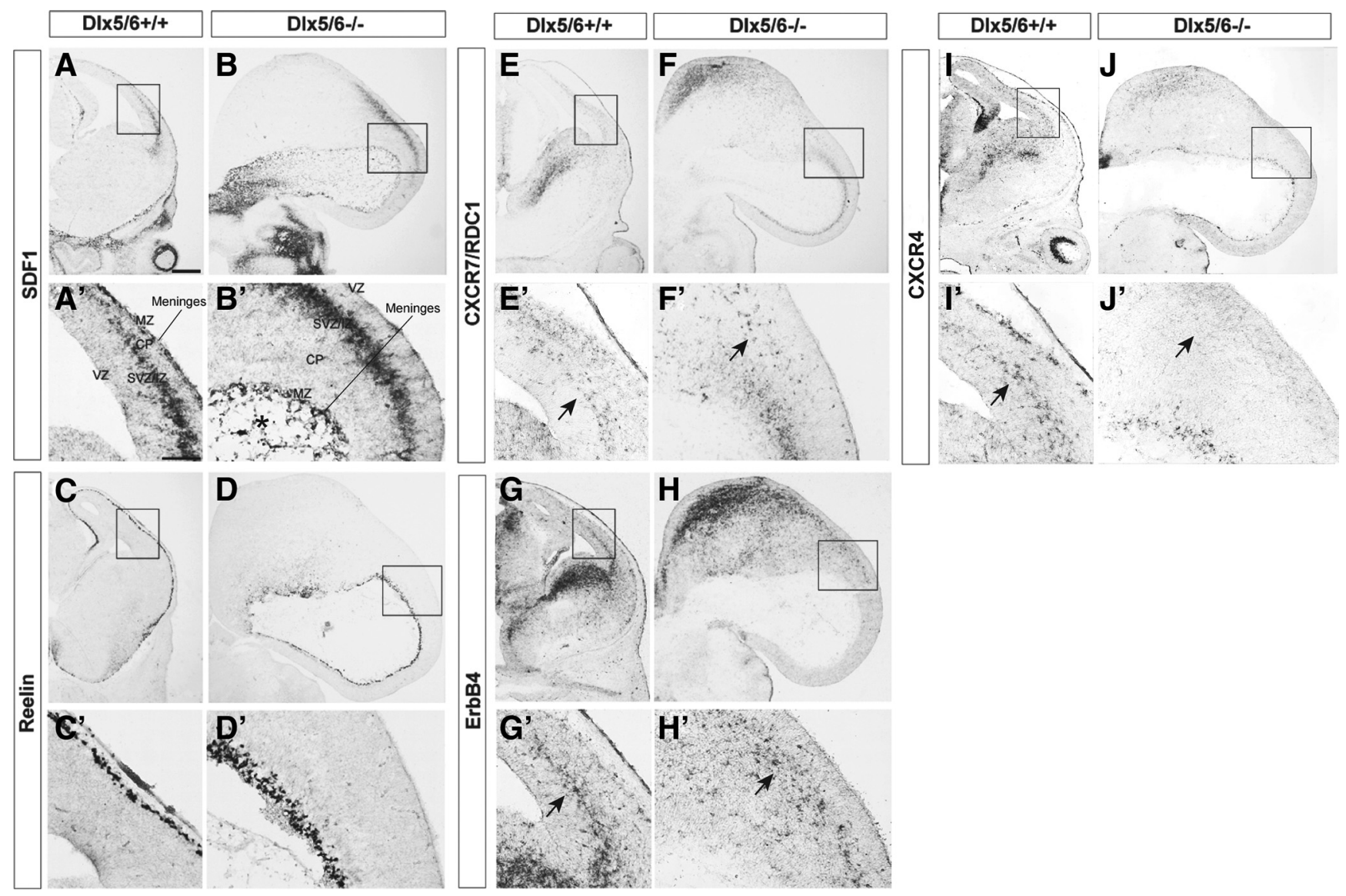

Figure 5. $A-J^{\prime}$, Loss of $C X C R 4$ expression in deep migratory interneurons of $D / \times 5 / 6^{-/-}$mutants at E13.5. Coronal sections from $D / \times 5 / 6^{+/+}(A, C, E, G, I)$ and $D / \times 5 / 6^{-/-}(B, D, F, H, J)$ were labeled by in situ hybridization against SDF1, Reelin, CXCR7 (RDC1), ErbB4 and CXCR4.Boxed areas are shown below in high magnification. The expression of SDF1 and reelin was maintained in $D / x 5 / 6^{-1-}$ mutants $(\boldsymbol{B}, \boldsymbol{D})$. The cavity formed by the everted exencephalic cortex contained scattered SDF1 ${ }^{+}$cells $\left({ }^{*}\right.$ in $\left.B^{\prime}\right)$. Although the expression of $C X C R 7$ and ErbB4 was intact, $C X C R 4$ expression was not detected in deep migratory interneurons (arrows in $\boldsymbol{E}^{\prime}, \boldsymbol{F}^{\prime}, \boldsymbol{G}^{\prime}, \boldsymbol{H}^{\prime}, \boldsymbol{I}^{\prime}, \boldsymbol{J}^{\prime}$ ). Scale bar: (in $\left.\boldsymbol{A}\right) \boldsymbol{A}-\boldsymbol{J}^{\prime}, 300 \mu \mathrm{m}$.

terneurons, we could not rule out the contribution of the exencephalic nature of the Dlx5/6 $6^{-1-}$ brain. To circumvent this caveat, we transplanted E13.5 Dlx5/6 ${ }^{-1-}$ mutant MGE cells into a wild-type P0 cortex. We used the Lhx6-BAC GFP transgene (which has previously been shown to label $\sim 75-85 \%$ of $\mathrm{PV}^{+}$and $55-70 \%$ of SST $^{+}$interneurons) (Cobos et al., 2006) as a reporter to follow the fate of MGE-derived offspring cells. Furthermore, to determine the individual role of $D l \times 5$ in cortical interneuron development, we performed the transplantation using MGE cells from Dl $x 5^{-1-}$ mutants (Long et al., 2003).

We analyzed the grafted cells at 1 and 2 months after transplantation. Of the 86 transplantations, 62 pups contained grafted cells, judged by GFP immunohistochemistry. Grafted interneuron precursors from $D l \times 5 / 6^{-1-}$ and $D l \times 5^{-1-}$ mutants were able to migrate, with leading migrating cells $4.0 \mathrm{~mm}$ away from the injection site along the rostral-caudal axis, and no differences were detected in the distribution of $\mathrm{GFP}^{+}$neurons between wildtype, $D l \times 5^{-1-}$, and $D l \times 5 / 6^{-1-}$ mutants (supplemental Fig. 6, available at www.jneurosci.org as supplemental material). This shows that the intracortical migration of $L h \times 6-\mathrm{GFP}^{+}$interneurons (at least postnatally) may not rely on $D l \times 5 / 6$ function.

Next, we compared the percentage of neurons that differentiated into $\mathrm{PV}^{+}, \mathrm{SST}^{+}, \mathrm{NPY}^{+}$, and calretinin ${ }^{+}$cells from the $D l \times 5 / 6^{+/+}, D l \times 5^{-1-}$ and $D l \times 5 / 6^{-1-}$ transplants (Fig. $6 A-$ $D)$. We only detected a phenotype for $\mathrm{PV}^{+}$interneurons. There was a $\sim 2$-fold reduction in Dl $\times 5^{-1-}$ transplants and a $\sim 3$-fold reduction in the Dlx5/6 ${ }^{-1-}$ transplants (Fig. $6 E$ )
$\left(D l x 5 / 6^{+/+}: 25.21 \pm 3.49 \% ; D l \times 5^{-/-}: 13.29 \pm 1.38 \% ; D l \times 5 / 6^{-/-}\right.$: $8.27 \pm 1.37 \% ; p<0.01)$.

Finally, to assess whether the $D l \times 5^{-1-}$ and $D l \times 5 / 6^{-1-}$ mutations affected the dendritic morphology of $\mathrm{PV}^{+}$grafted cells, we studied confocal images using NIH ImageJ software. Dendritic arborization of the grafted $\left(\mathrm{GFP}^{+}\right) \mathrm{PV}^{+}$cells could be assessed in isolated interneurons (Fig. $6 F, F^{\prime}$ ); we manually traced the dendritic arbors of 15 cells from each genotype and measured the number of processes, total dendritic length, average dendritic length, and longest dendrite (Fig. 6G). The Dlx5/6 ${ }^{-1-}$ mutant cells showed a statistically significant increase in the number of processes compared with cells from $D l \times 5 / 6^{+/+}$and $D l \times 5^{-1-}$ donors $\left(D l \times 5 / 6^{+/+}: 10.00 \pm 0.71 \% ; D l x 5^{-/-}: 9.67 \pm 0.25 \%\right.$; Dlx5/6 ${ }^{-1-}: 19.33 \pm 0.71 \% ; p<0.01$ ) (Fig. $6 H$ ). Accordingly, $\mathrm{PV}^{+}$cells from $\mathrm{D} l \times 5 / 6^{-1-}$ tended to display an increase in total dendritic length (Fig. 6I). However, average dendritic length, length of the longest dendrite of $\mathrm{PV}^{+}$cells from $D l \times 5 / 6^{-1-}$ decreased by the $\sim 25 \%$ and $35 \%$ respectively (Fig. $6 \mathrm{~J}, \mathrm{~K}$ ). Dendritic morphology of $D l \times 5^{-1-}$ mutants was only mildly affected.

\section{Dlx5/6 are not essential for short-term in vitro cell survival of MGE cultures}

The reduced numbers of cortical interneurons in the embryonic Dl $\times 5 / 6^{-1-}$ mutants, and the reduced fraction of $\mathrm{PV}^{+}$interneurons transplanted from the MGE of $D l \times 5 / 6^{-1-}$ could be due to reduced survival of these cells. $D l x 1$ and $D l \times 2$ are known to promote neuronal survival. For instance, $D l \times 1^{-1-}$ mutants have in- 
creased cell death of subsets of postnatal cortical interneurons, and $D l \times 1 / 2^{-1-} \mathrm{mu}-$ tants have massive prenatal cell death in vivo in the basal ganglia and in vitro in cultures derived from the MGE of Dlx $1 /$ $2^{-1-}$ mutants (Cobos et al., 2007). Note that loss of $D l x 1 \& 2$ expression in the MGE results in loss of Dlx $\& 6$ expression (Anderson et al., 1997a). Thus, to test whether MGE-derived cells of Dlx5/6 mutants have reduced survival, we used the in vitro culture assay described by Cobos et al. (2007). Unlike the Dlx $1 / 2^{-1-}$ mutants, which have $>95 \%$ cell death after $10 \mathrm{~d}$ in vitro, the $D l \times 5 / 6^{-1-}$ mutant MGE cells showed indistinguishable survival compared with $D l \times 5 / 6^{+/+}$cells for up to $40 \mathrm{~d}$ in vitro (supplemental Fig. 7 , available at www.jneurosci.org as supplemental material). Furthermore, cell death analysis at embryonic stages (supplemental Fig. 8, available at www.jneurosci.org as supplemental material) or of the transplanted cortex showed no evidence of increased apoptosis 15 and $30 \mathrm{~d}$ after transplantation by TUNEL staining and anti-active caspase- 3 immunohistochemistry (data not shown).

Finally, there could be reduced proliferation in the Dlx5/6 ${ }^{-1-}$ MGE leading to reduced interneuron production. While we have not definitively ruled this out, our analysis of $\mathrm{M}$ phase cells $\left(\mathrm{PH}^{+}\right)$(supplemental Fig. 9, available at www.jneurosci. org as supplemental material) and growth in MGE cultures did not detect an obvious phenotype.

\section{Cellular characterization of neocortical interneurons from Dlx 5 BAC transgenic mouse line}

The transplantation results show that $D l \times 5$ and $D l \times 5 / 6$ are required for the development of a substantial fraction of $\mathrm{PV}^{+}$neocortical interneurons (Fig. 6). The expression of Dlx5 and Dlx6 in maturing and adult cortical interneurons has previously not been examined, thus we sought to explore whether their expression present in $\mathrm{PV}^{+}$interneuron. Unfortunately, we do not have antibodies that specifically detect their DLX5 or DLX6 proteins, and therefore we used other methods to detect their expression. We assessed Dlx6 expression in the postnatal brain by in situ hybridization and by using LacZ expression from the Dlx6 locus. Neither assay showed robust expression (data not shown), although the Allen Brain Atlas does detect its expression in low numbers of scattered neocortical cells, consistent with its expression in a small subset of interneurons. Thus, in addition to its expression in the subventricular zone of the MGE and CGE (where it can regulate the early development of cortical interneurons), $D l x 6$ may also express in adult cortical interneurons.

To assess Dlx 5 expression, we used the Dlx5-GFP BAC transgenic mouse line, in which EGFP reporter gene is inserted immediately upstream of the coding sequence of the Dlx5 gene. We began by analyzing GFP expression in tangentially migrating cor-

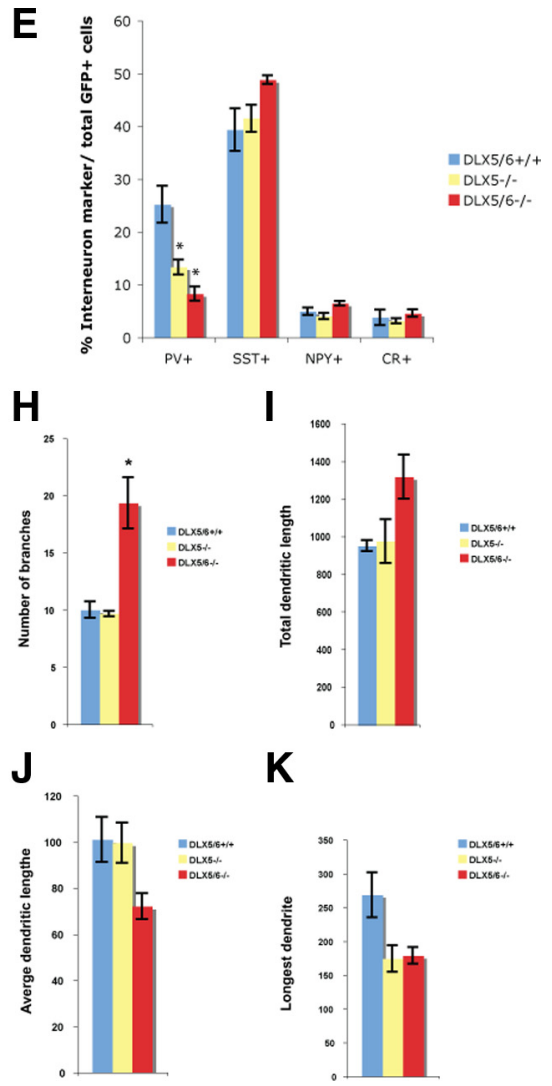

H

Figure 6. Cell-autonomous role for D/x5/6 in controlling differentiation of PV ${ }^{+}$cortical interneurons. E13.5 control $(+/+)$, or D1X5/6 MGE cells. $F, F$, To analyze the morphology of GFP ${ }^{+} / P V$

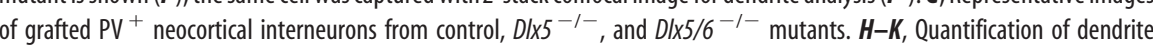

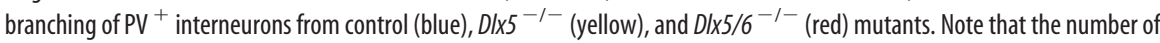
branches is increased in D/x5/6 ${ }^{-/-}$grafted PV ${ }^{+}$interneurons. Scale bar: (in $\boldsymbol{F}^{\prime}$ ) $\boldsymbol{A}-\boldsymbol{F}^{\prime}, 100 \mu \mathrm{m}$.

tical interneurons at E15.5. Double-labeling immunohistochemistry was performed with anti-DLX2 (Kuwajima et al., 2006) and anti-GFP antibodies. We found that not all immature interneurons coexpress DLX2 and DLX5 in the marginal zone (MZ), cortical plate (CP) and intermediate zone/subventricular zone (IZ/ SVZ) of the developing cortex. Roughly one-third of cells were Dlx5-GFP- (supplemental Fig. 9, available at www.jneurosci.org as supplemental material) $(30.18 \pm 2.65 \%, 30.73 \pm 2.96 \%$ and $41.86 \pm 1.96 \%$ in MZ, CP, and IZ/SVZ, respectively). Furthermore, there was a small subpopulation of Dlx5-GFP ${ }^{+}$cells that were DLX2 ${ }^{-}$(supplemental Fig. 10, available at www.jneurosci. org as supplemental material) $(10.21 \pm 0.71 \%$ in MZ, $10.02 \pm$ $0.67 \%$ in CP, $2.25 \pm 0.16 \%$ in IZ/SVZ, respectively).

Next we examined Dlx5-GFP expression in the adult (P60) somatosensory cortex. We assessed its expression among different interneuron populations in layers II-IV and layers V-VI. In layers II-IV, we found that Dlx5-GFP was rather evenly distributed among $\mathrm{PV}^{+}, \mathrm{SST}^{+}, \mathrm{NPY}^{+}$, and $\mathrm{CR}^{+}$interneurons (23.97 \pm $2.60 \%$ in $\mathrm{PV}^{+}, 17.49 \pm 4.95 \%$ in SST ${ }^{+}, 18.11 \pm 2.46 \%$ in $\mathrm{NPY}^{+}$, $30.13 \pm 2.4 \%$ in $\mathrm{CR}^{+}$interneurons) (Fig. $7 F$ ). On the other hand in layers V-VI, Dlx5-GFP was predominantly expressed in $\mathrm{PV}^{+}$ 


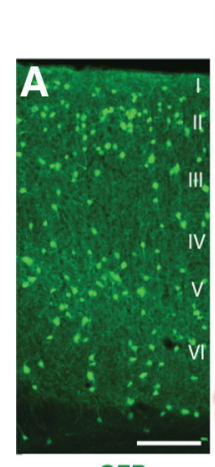

GFP
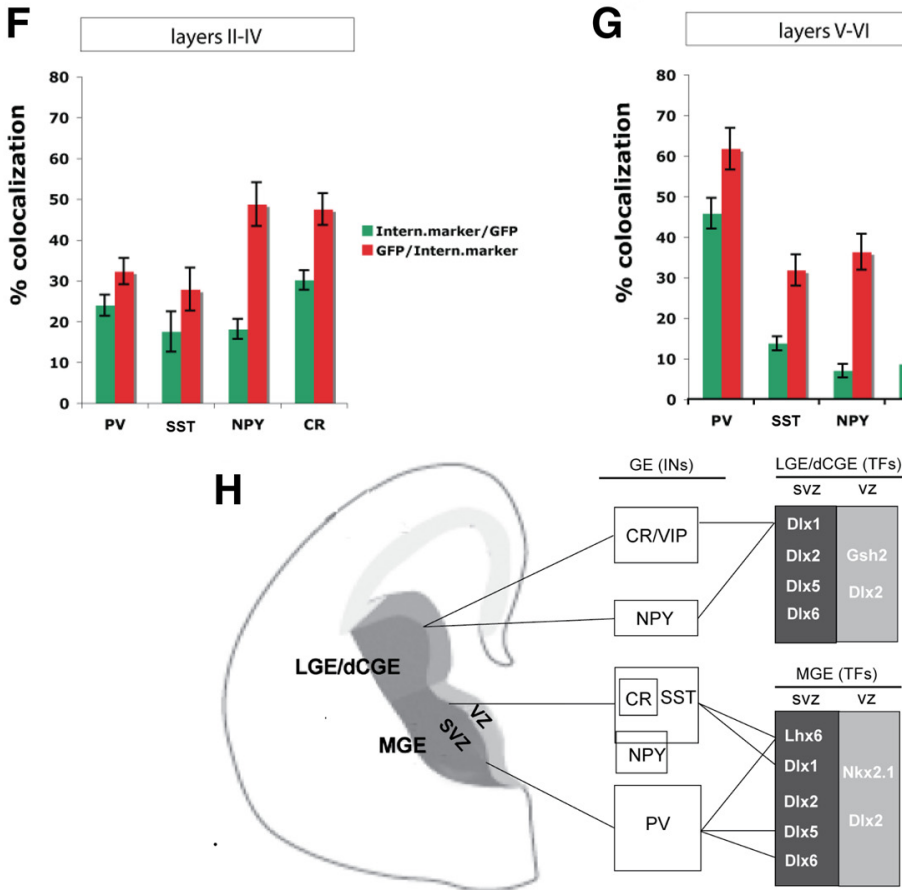

Figure 7. Characterization of GFP expression in adult neocortical interneurons from the D/x5 BAC transgenic mouse. $\boldsymbol{A}$, GFP immunofluorescence in coronal sections through somatosensory cortex at 2 months of age. $\boldsymbol{B}-\boldsymbol{E}$, Double immunofluorescence confocal images with anti-GFP and anti-PV $(\boldsymbol{B})$, anti-SST $(\boldsymbol{C})$, anti-NPY (D), or anti-CR $(\boldsymbol{E})$ antibodies. $\boldsymbol{F}, \boldsymbol{G}$, Quantification of the percentage of GFP ${ }^{+}$cells that express each of the different interneuron markers (green bar) and the percentage of PV, SST, NPY, or CR cells that express GFP (red bar) in layer II-IV $(\boldsymbol{F})$ and layer V-VI (G). $\boldsymbol{H}$, Model of transcription factors that control the development of cortical and hippocampal interneurons. LGE/dCGE (dorsal CGE) are proposed to generate CR/VIP ${ }^{+}$and a subset of NPY ${ }^{+}$(late born) interneurons, which express D/x 1 and require it for their survival. The dorsal MGE generates SST ${ }^{+}$(including SST/CR ${ }^{+}$and SST/NPY ${ }^{+}$) interneurons that express DIx 1 and $L h \times 6$, and require them for their survival and differentiation, respectively. The ventral MGE produces $\mathrm{PV}^{+}$interneurons that express D/X5 and $L h \times 6$, and require D/X5, D/x6, and $L h \times 6$ for their differentiation. Scale bar: (in $\boldsymbol{E}) \boldsymbol{A}-\boldsymbol{E}, 100 \mu \mathrm{m}$.

Spontaneous electrographic seizures and reduced maximum gamma power in Dlx $5 / 6^{+/-}$heterozygotes in the absence of gross histological abnormalities

Adult $D l \times 1^{-/-}$mice exhibit generalized electrographic seizures (Cobos et al. 2005), suggesting that $D l \times 5 / 6$ mutants may also have epilepsy. To circumvent the embryonic lethality of $D l \times 5 / 6^{-1-}$ mice and determine whether reduced $D l \times 5 / 6$ dosage has a functional consequence, we performed video-EEG monitoring and histological studies in adult (4-6 months of age) $D l \times 5 / 6^{+/-}$(heterozygous) mice.

We quantified the total number of cells expressing PV, SST, CR and NPY within a $380,000 \mu \mathrm{m}^{2}$ region of somatosensory cortex; no significant differences were observed (Fig. 8A-I). Next, we performed video-EEG monitoring on Dlx5/6 ${ }^{+/-}$ $(n=5)$ and age-matched littermate control mice $(n=5)>4$ months of age during awake, freely moving behavior (Fig. $8 \mathrm{~J}$ ). Seventeen distinct electrographic seizure events ( $32.5 \pm 6.4$ s duration) were confirmed in EEG recordings from four of the five $D l \times 5 / 6^{+/-}$mice. Representative events from $D l \times 5 / 6^{+/+}$and $D l \times 5 /$ $6^{+/-}$mice are shown in Figure $8 \mathrm{~J}$. Electrographic events from $D l \times 5 / 6^{+/-}$ mice began with a brief period of highfrequency activity evolving into sharp high voltage spikes and polyspike bursting (Fig. $8 \mathrm{Jb}$ ). Behaviors associated with these events were subtle and sometimes comprised a brief period of arrest with a slight head jerk. Electrographic seizure or behavior was never observed in control animals (Fig. $8 \mathrm{Ja}$ ). Thus, reduced $D l \times 5 / 6$ dosage appears to result in abnormal cortical function (i.e., seizures) despite the absence of gross anatomical abnormalities.

We hypothesized that the cortical hyperexcitability of $D l \times 5 / 6^{+/-}$mice might be due to the functional deficits of $\mathrm{PV}^{+}$ interneuron. We based this idea on our evidence that $D l x 5 / 6$ regulate prenatal development of the $\operatorname{Lh} x 6^{+}$neurons (Fig. 4),

interneurons $\left(45.8 \pm 3.75 \%\right.$ in $\mathrm{PV}^{+}, 13.75 \pm 1.71 \%$ in $\mathrm{SST}^{+}$, $6.97 \pm 1.62 \%$ in $\mathrm{NPY}^{+}, 8.62 \pm 1.02 \%$ in $\mathrm{CR}^{+}$interneurons (Fig. $7 G$ ).

We also performed fate mapping experiments on $D l \times 5 / 6-$ lineage neocortical interneurons by crossing Dlx5/6i-cre mice (Kohwi et al., 2007) into Rosa-YFP Cre reporter mice. Similarly, we found that $\mathrm{GFP}^{+}$cells were predominately expressed in $\mathrm{PV}^{+}$interneurons in layers V-VI $\left(41.09 \pm 1.76 \%\right.$ in $\mathrm{PV}^{+}$, $15.15 \pm 2.35 \%$ in $\mathrm{SST}^{+}, 5.37 \pm 0.89 \%$ in $\mathrm{NPY}^{+}, 8.52 \pm 2.05 \%$ in $\mathrm{CR}^{+}$interneurons) (supplemental Fig. 11, available at www. jneurosci.org as supplemental material). Thus, unlike Dlx1, which appears to be excluded from $\mathrm{PV}^{+}$interneurons, Dlx5 is expressed in this interneuron subtype, and based on our transplantation data, is required for their development. and regulate the number and dendritic morphology of $\mathrm{PV}^{+}$cortical interneurons (Fig. 6). Because $\mathrm{PV}^{+}$interneurons are thought to regulate gamma oscillations (Fuchs et al., 2007; Cardin et al., 2009; Sohal et al., 2009), we investigated the power in the different frequency bands in the EEG recording during periods of awake, freely moving mice. First we used wavelet analysis to measure the power in frequency bands between 4 and $200 \mathrm{~Hz}$ in EEG recorded from both $D l \times 5 / 6^{+/+}$and $D l \times 5 / 6^{+/-}$mice $(n=4$ mice per group). We analyzed five, 60 -s-long recordings from two sites in each animal. We found that $D l \times 5 / 6^{+/-}$mice exhibited a selective $45 \pm 18 \%$ increase in the total power between 152 and $200 \mathrm{~Hz}(p<$ 0.05 by one-way ANOVA; $n=40$ recordings in each group).

Next we investigated whether gamma oscillations were affected in $D l \times 5 / 6^{+/-}$mice. However, because the presence of 
gamma oscillations is highly dependent on specific behaviors, we reasoned that gamma oscillations might not be present in all of the recordings. Therefore, for each set of recordings (five $60 \mathrm{~s}$ recordings from each site in each mouse), we selected the $60 \mathrm{~s}$ recording with maximum power in the gammarange $(30-80 \mathrm{~Hz})$. We found that maximum gamma power was reduced by $33 \pm 11 \%$ in $D l x 5 / 6^{+/-}$mice $(p<0.05$ by one-way ANOVA; $n=8$ recordings in each group). The reduced maximum gamma power in $D l \times 5 / 6^{+/-}$mice, and the defects in transplanted $D l \times 5 / 6^{-1-} \mathrm{PV}^{+}$interneurons, provide evidence that $D l \times 5 / 6$ regulate both the development and function of $\mathrm{PV}^{+}$ interneurons.

\section{Discussion}

We provide evidence that $D l x 5 \& 6$ promote the prenatal tangential migration of cortical interneurons, in part through CXCR4 expression, and that postnatally $D l \times 5 \& 6$ are preferentially required for the development and dendritic morphology of $\mathrm{PV}^{+}$interneurons. While the cortex of $D l \times 5 / 6^{+/-}$heterozygous mice appears anatomically normal, they have epilepsy and reduced power in their gamma oscillations, suggesting a defect in the function of their $\mathrm{PV}^{+}$interneurons.

\section{Normal patterning and differentiation in the embryonic basal ganglia of the exencephalic Dlx5/6 ${ }^{-/-}$mutants}

Despite the fact that the embryos are excencephalic (Robledo et al., 2002), we found that regionalization of the telencephalon was remarkably intact, based on the appropriate regional expression of pallial (e.g., Tbr1), striatal (e.g., Ikaros, $R X R \gamma$ ) and pallidal (e.g., ErbB4, Lhx6) markers, and the generation of subpallium-derived cortical interneurons (Figs. 1-5; supplemental Figs. 1, 2, available at www.jneurosci.org as supplemental material). However, because these mutants degenerate after $\sim$ E16.5, and because of their exencephalic state, we cannot conclude that subpallial differentiation is entirely intact. It is probable that persistent expression of $D l x 1 \& 2$ (Figs. 1-3) can partially compensate for lack of $D l x 5 \& 6$.

\section{Reduced numbers of tangentially migrating $\operatorname{Lhx6^{+}}$ and $\mathrm{MafB}^{+}$cortical interneurons}

The cortex of $D l \times 5 / 6^{-1-}$ mutants has reduced numbers of cells expressing markers of tangentially migrating immature interneurons (Figs. 2-4). At E16.5, there is a disproportionate reduction in the expression of $\operatorname{Lh} x 6$ and $M a f B$ in the MZ, compared with $D l x 1$, suggesting that $D l x 5 \& 6$ are preferentially required for the

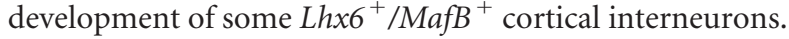

There are at least two types of tangentially migrating interneurons: $D l x^{+}$and $D l x^{+} ; L h x 6^{+}$(Zhao et al., 2008). Lhx6 function is required for $M a f B$ expression and for the production of $\mathrm{PV}^{+}$and SST $^{+}$interneurons (Liodis et al., 2007; Zhao et al., 2008). Thus, the preferential reduction of $L h \times 6$ and $M a f B$ suggests that $D l \times 5 \& 6$ have key roles in the development of $\mathrm{PV}^{+}$and $\mathrm{SST}^{+}$interneurons. Indeed, transplantation of $D l \times 5^{-/-}$and $D l \times 5 / 6^{-/-}$mutant MGE cells results in fewer $\mathrm{PV}^{+}$neocortical interneurons (Fig. 6). The observation that $\mathrm{SST}^{+}$interneurons are not reduced supports a hypothesis that $D l x 5$ and $D l x 5 \& 6$ are more important in promoting the PV subtype; perhaps the subset of $L h x 6^{+}$interneurons that do migrate into the mutant embryonic cortex will become SST ${ }^{+}$.

We have not elucidated the mechanism(s) whereby Dlx5 and Dlx $\& \& 6$ control PV interneuron development. There is clearly a defect in the efficiency of tangential migration and an apparent 
accumulation of $L h x 6^{+}$cells in the region of the MGE (Fig. 3, arrows). We studied the expression of receptors expressed on the tangentially migrating cells that are implicated in regulating their migration (CXCR4, CXCR7, ErbB4). There was a clear reduction in CXCR4 expression in cortical SVZ/IZ (Fig. 5). Given the known function of CXCR4 (Stumm et al., 2003; Li et al., 2008; Liapi et al., 2008; Lopez-Bendito et al., 2008; Tiveron and Cremer, 2008 ), this defect could contribute to the slowing of tangential migration in the $D l \times 5 / 6^{-1-}$ mutants.

\section{Reduced numbers of $\mathrm{PV}^{+}$neocortical interneurons in Dl $x 5^{-1-}$ and Dl $x 5 / 6^{-/-}$MGE transplants suggests a Dlx transcriptional code for interneuron development}

Transplantation of mutant MGE into neonatal wild-type cortex showed a selective deficit in the formation of $\mathrm{PV}^{+}$interneurons; there was a $\sim 2$-fold reduction in Dlx $5^{-1-}$ transplants and a $\sim 3$ fold reduction in the $D l \times 5 / 6^{-1-}$ transplants (Fig. 6). It strongly suggests a cell-autonomous requirement for $D l \times 5 / 6$ in the development of $\mathrm{PV}^{+}$interneurons. The $D l \times 5^{-1-}$ phenotype was less severe than Dlx5/6 $6^{-1-}$ phenotype; this provides evidence that Dlx 6 contributes to the development of $\mathrm{PV}^{+}$interneurons. Dlx6 expression is weakly detected in the MGE SVZ (Anderson et al., 1997a), where it could, in conjunction with $D l x 5$, promote $L h x 6$ expression. Notably, Dl $\times 1 / 2^{-1-}$ mutants have a modest reduction in Lhx6 expression in the MGE SVZ (Petryniak et al., 2007). However, there is no obvious reduction in Lhx6 (or Lhx6-GFP) expression in the $D l \times 5 / 6^{-1-}$ MGE SVZ; rather there may be increased expression (Figs. 2, 3). It is possible that $D l \times 5 \& 6$ promote Lhx6 expression in developing $\mathrm{PV}^{+}$interneurons, and not in developing $\mathrm{SST}^{+}$interneurons. Alternatively, lack of $\mathrm{Dl} \times 5 / 6$ could alter cell identity. While there is no definitive data showing this, there is a slight increase in $\mathrm{SST}^{+}$cells in the transplants (Fig. 6).

$\mathrm{PV}^{+}$and $\mathrm{SST}^{+}$interneurons appear to arise preferentially from distinct dorsoventral domains of the MGE (Flames et al., 2007). The genetic mechanisms that differentially regulate their development are just beginning to be understood. Prenatally, $D l x l$ and $L h x 6$ are initially expressed in most migrating interneurons; late in gestation a larger subset express only $D l x 1$ (Zhao et al., 2008). By adulthood, their expression becomes further restricted to specific subtypes. Dlxl expression is not detected in $\mathrm{PV}^{+}$interneurons, whereas it is expressed in most $\mathrm{CR}^{+}$interneurons and subsets of SST ${ }^{+}$and $\mathrm{NPY}^{+}$interneurons; Lhx6 is expressed in most $\mathrm{PV}^{+}$and $\mathrm{SST}^{+}$interneurons and a small subsets of $\mathrm{CR}^{+}$and $\mathrm{NPY}^{+}$interneurons (Cobos et al., 2005). Here we show that while Dlx5 is broadly expressed prenatally in migrating interneurons, its expression in adult deep cortical layers is preferentially restricted to $\mathrm{PV}^{+}$interneurons (Fig. $7 A-H$ ). Thus, current evidence supports a model that $D l \times 1$ and $D l \times 5$ show differential expression and function in distinct subtypes of cortical interneurons: Dlxl in $L h x 6^{-}$interneurons that express SST, CR and NPY, and Dlx 5 in $L h x 6^{+}$interneurons that express PV (Fig. $7 H$ ).

\section{Spontaneous electrographic seizures and reduced maximum gamma power in $\mathrm{Dl} \times 5 / 6^{+/-}$heterozygotes}

Clinical and experimental evidence demonstrating an impairment of GABA-mediated inhibition in epilepsy is quite common (Treiman, 2001). Loss of GABA-producing interneurons is considered a critical aspect of this impairment and has been observed in tissue sections from patients with intractable epilepsy (Knopp et al., 2008) and more recently, in mutant mice (Powell et al., 2003; Cobos et al., 2005; Marsh et al., 2005; Glickstein et al., 2007;
Butt et al., 2008; Marsh et al., 2009). These findings contribute to an emerging concept that epileptic disorders associated with interneuron dysfunction could be classified as an "interneuronopathy" (Kato and Dobyns, 2005). Our analysis of Dlx5/6 $6^{+/-}$mutants is consistent with this classification and indicates that reduced Dlx5/6 dosage results in brief spontaneous electrographic seizures. This is an interesting finding given that we did not detect a frank decrease in interneuron density in the cortex or hippocampus of these animals. However, because we did observe impairment in the dendritic/axonal arbors of $\mathrm{PV}^{+}$interneurons from Dl $\times 5 / 6^{-1-}$ mutant transplants, these findings suggest that epilepsy can be associated with subtle changes in interneuron structure. That altered $\mathrm{PV}^{+}$interneuron morphology leads to functional impairment was further confirmed in our observations of reduced gamma power in the EEG recordings; gamma waves a signature of $\mathrm{PV}^{+}$interneuron function (Fuchs et al., 2007; Cardin et al., 2009; Sohal et al., 2009). As such, we hypothesize that $D l \times 5 / 6$ regulates postnatal properties of $\mathrm{PV}^{+}$interneurons. Future studies are needed to establish the cellular and molecular basis of this physiological phenotype, although clues could be found in the recent paper describing developmental gene expression in $\mathrm{PV}^{+}$interneurons (Okaty et al., 2009).

The observation of electrophysiological defects in Dl $\times 5 / 6^{+/-}$ mice is important as it provides the first evidence that reduced gene dosage (heterozygosity of a loss of function allele) of transcription factors result in epilepsy, and yet show no obvious anatomical defect (Fig. 8). This finding may be germane to human neuropsychiatric disorders, where geneticists are discovering mutations in heterozygosity states. For instance, we have identified autistic probands who are heterozygous for two types of nonsynonymous mutations in Dlx5 (Hamilton et al., 2005).

\section{References}

Anderson SA, Qiu M, Bulfone A, Eisenstat DD, Meneses J, Pedersen R, Rubenstein JL (1997a) Mutations of the homeobox genes Dlx-1 and Dlx-2 disrupt the striatal subventricular zone and differentiation of late born striatal neurons. Neuron 19:27-37.

Anderson SA, Eisenstat DD, Shi L, Rubenstein JL (1997b) Interneuron migration from basal forebrain to neocortex: dependence on Dlx genes. Science 278:474-476.

Baraban SC, Southwell DG, Estrada RC, Jones DL, Sebe JY, Alfaro-Cervello C, Garcia-Verdugo JM, Rubenstein JL, Alvarez-Buylla A (2009) Reduction of seizures by transplantation of cortical GABAergic interneuron precursors into Kv1.1 mutant mice. Proc Natl Acad Sci U S A 106:15472-15477.

Bielle F, Griveau A, Narboux-Neme N, Vigneau S, Sigrist M, Arber S, Wassef M, Pierani A (2005) Multiple origins of Cajal-Retzius cells at the borders of the developing pallium. Nat Neurosci 8:1002-1012.

Borrell V, Marin O (2006) Meninges control tangential migration of hemderived Cajal-Retzius cells via CXCL12/CXCR4 signaling. Nat Neurosci 9:1284-1293

Butt SJ, Fuccillo M, Nery S, Noctor S, Kriegstein A, Corbin JG, Fishell G (2005) The temporal and spatial origins of cortical interneurons predict their physiological subtype. Neuron 48:591-604.

Butt SJ, Sousa VH, Fuccillo MV, Hjerling-Leffler J, Miyoshi G, Kimura S, Fishell G (2008) The requirement of Nkx2-1 in the temporal specification of cortical interneuron subtypes. Neuron 59:722-732.

Cardin JA, Carlen M, Meletis K, Knoblich U, Zhang F, Deisseroth K, Tsai LH, Moore CI (2009) Driving fast-spiking cells induces gamma rhythm and controls sensory responses. Nature 459:663-667.

Cobos I, Calcagnotto ME, Vilaythong AJ, Thwin MT, Noebels JL, Baraban SC, Rubenstein JL (2005) Mice lacking Dlx1 show subtype-specific loss of interneurons, reduced inhibition and epilepsy. Nat Neurosci 8:10591068.

Cobos I, Long JE, Thwin MT, Rubenstein JL (2006) Cellular patterns of transcription factor expression in developing cortical interneurons. Cereb Cortex 16 [Suppl 1]:i82-i88.

Cobos I, Borello U, Rubenstein JL (2007) Dlx transcription factors promote 
migration through repression of axon and dendrite growth. Neuron 54:873-888.

Colasante G, Collombat P, Raimondi V, Bonanomi D, Ferrai C, Maira M, Yoshikawa K, Mansouri A, Valtorta F, Rubenstein JL, Broccoli V (2008) Arx is a direct target of Dlx2 and thereby contributes to the tangential migration of GABAergic interneurons. J Neurosci 28:10674-10686.

Colombo E, Collombat P, Colasante G, Bianchi M, Long J, Mansouri A, Rubenstein JL, Broccoli V (2007) Inactivation of Arx, the murine ortholog of the X-linked lissencephaly with ambiguous genitalia gene, leads to severe disorganization of the ventral telencephalon with impaired neuronal migration and differentiation. J Neurosci 27:4786-4798.

Depew MJ, Liu JK, Long JE, Presley R, Meneses JJ, Pedersen RA, Rubenstein JL (1999) Dlx5 regulates regional development of the branchial arches and sensory capsules. Development 126:3831-3846.

Depew MJ, Lufkin T, Rubenstein JL (2002) Specification of jaw subdivisions by Dlx genes. Science 298:381-385.

Du T, Xu Q, Ocbina PJ, Anderson SA (2008) NKX2.1 specifies cortical interneuron fate by activating Lhx6. Development 135:1559-1567.

Flames N, Marin O (2005) Developmental mechanisms underlying the generation of cortical interneuron diversity. Neuron 46:377-381.

Flames N, Pla R, Gelman DM, Rubenstein JL, Puelles L, Marin O (2007) Delineation of multiple subpallial progenitor domains by the combinatorial expression of transcriptional codes. J Neurosci 27:9682-9695.

Fogarty M, Grist M, Gelman D, Marin O, Pachnis V, Kessaris N (2007) Spatial genetic patterning of the embryonic neuroepithelium generates GABAergic interneuron diversity in the adult cortex. J Neurosci 27:10935-10946.

Fuchs EC, Zivkovic AR, Cunningham MO, Middleton S, Lebeau FE, Bannerman DM, Rozov A, Whittington MA, Traub RD, Rawlins JN, Monyer H (2007) Recruitment of parvalbumin-positive interneurons determines hippocampal function and associated behavior. Neuron 53:591-604.

Fulp CT, Cho G, Marsh ED, Nasrallah IM, Labosky PA, Golden JA (2008) Identification of Arx transcriptional targets in the developing basal forebrain. Hum Mol Genet 17:3740-3760.

Glickstein SB, Moore H, Slowinska B, Racchumi J, Suh M, Chuhma N, Ross ME (2007) Selective cortical interneuron and GABA deficits in cyclin D2-null mice. Development 134:4083-4093.

Hamilton SP, Woo JM, Carlson EJ, Ghanem N, Ekker M, Rubenstein JL (2005) Analysis of four DLX homeobox genes in autistic probands. BMC Genet 6:52.

Hammond V, So E, Gunnersen J, Valcanis H, Kalloniatis M, Tan SS (2006) Layer positioning of late-born cortical interneurons is dependent on Reelin but not p35 signaling. J Neurosci 26:1646-1655.

Hevner RF, Daza RA, Englund C, Kohtz J, Fink A (2004) Postnatal shifts of interneuron position in the neocortex of normal and reeler mice: evidence for inward radial migration. Neuroscience 124:605-618.

Kato M, Dobyns WB (2005) X-linked lissencephaly with abnormal genitalia as a tangential migration disorder causing intractable epilepsy: proposal for a new term, "interneuronopathy." J Child Neurol 20:392-397.

Kitamura K, Yanazawa M, Sugiyama N, Miura H, Iizuka-Kogo A, Kusaka M, Omichi K, Suzuki R, Kato-Fukui Y, Kamiirisa K, Matsuo M, Kamijo S, Kasahara M, Yoshioka H, Ogata T, Fukuda T, Kondo I, Kato M, Dobyns WB, Yokoyama M, Morohashi K (2002) Mutation of ARX causes abnormal development of forebrain and testes in mice and X-linked lissencephaly with abnormal genitalia in humans. Nat Genet 32:359-369.

Knopp A, Frahm C, Fidzinski P, Witte OW, Behr J (2008) Loss of GABAergic neurons in the subiculum and its functional implications in temporal lobe epilepsy. Brain 131:1516-1527.

Kohwi M, Petryniak MA, Long JE, Ekker M, Obata K, Yanagawa Y, Rubenstein JL, Alvarez-Buylla A (2007) A subpopulation of olfactory bulb GABAergic interneurons is derived from Emx1- and Dlx5/6-expressing progenitors. J Neurosci 27:6878-6891.

Kuwajima T, Nishimura I, Yoshikawa K (2006) Necdin promotes GABAergic neuron differentiation in cooperation with Dlx homeodomain proteins. J Neurosci 26:5383-5392.

Levi G, Puche AC, Mantero S, Barbieri O, Trombino S, Paleari L, Egeo A, Merlo GR (2003) The Dlx5 homeodomain gene is essential for olfactory development and connectivity in the mouse. Mol Cell Neurosci 22:530-543.

Li G, Adesnik H, Li J, Long J, Nicoll RA, Rubenstein JL, Pleasure SJ (2008) Regional distribution of cortical interneurons and development of inhib- itory tone are regulated by Cxcl12/Cxcr4 signaling. J Neurosci 28:10851098.

Liapi A, Pritchett J, Jones O, Fujii N, Parnavelas JG, Nadarajah B (2008) Stromal-derived factor 1 signalling regulates radial and tangential migration in the developing cerebral cortex. Dev Neurosci 30:117-131.

Liodis P, Denaxa M, Grigoriou M, Akufo-Addo C, Yanagawa Y, Pachnis V (2007) Lhx6 activity is required for the normal migration and specification of cortical interneuron subtypes. J Neurosci 27:3078-3089.

Long JE, Garel S, Depew MJ, Tobet S, Rubenstein JL (2003) DLX5 regulates development of peripheral and central components of the olfactory system. J Neurosci 23:568-578.

Long JE, Garel S, Alvarez-Dolado M, Yoshikawa K, Osumi N, Alvarez-Buylla A, Rubenstein JL (2007) Dlx-dependent and -independent regulation of olfactory bulb interneuron differentiation. J Neurosci 27:3230-3243.

Long JE, Swan C, Liang WS, Cobos I, Potter GB, Rubenstein JL (2009a) Dlx1\&2 and Mash1 transcription factors control striatal patterning and differentiation through parallel and overlapping pathways. J Comp Neurol 512:556-572.

Long JE, Cobos I, Potter GB, Rubenstein JL (2009b) Dlx1 and Mash1 transcription factors control MGE and CGE patterning and differentiation through parallel and overlapping pathways. Cereb Cortex 19 [Suppl 1]:i96-i106.

Lopez-Bendito G, Sanchez-Alcaniz JA, Pla R, Borrell V, Pico E, Valdeolmillos M, Marin O (2008) Chemokine signaling controls intracortical migration and final distribution of GABAergic interneurons. J Neurosci 28:1613-1624.

Marin O, Anderson SA, Rubenstein JL (2000) Origin and molecular specification of striatal interneurons. J Neurosci 20:6063-6076.

Marin O, Plump AS, Flames N, Sanchez-Camacho C, Tessier-Lavigne M, Rubenstein JL (2003) Directional guidance of interneuron migration to the cerebral cortex relies on subcortical Slit1/2-independent repulsion and cortical attraction. Development 130:1889-1901.

Marsh E, Melamed SE, Barron T, Clancy RR (2005) Migrating partial seizures in infancy: expanding the phenotype of a rare seizure syndrome. Epilepsia 46:568-572.

Marsh E, Fulp C, Gomez E, Nasrallah I, Minarcik J, Sudi J, Christian SL, Mancini G, Labosky P, Dobyns W, Brooks-Kayal A, Golden JA (2009) Targeted loss of Arx results in a developmental epilepsy mouse model and recapitulates the human phenotype in heterozygous females. Brain 132:1563-1576.

Okaty BW, Miller MN, Sugino K, Hempel CM, Nelson SB (2009) Transcriptional and electrophysiological maturation of neocortical fastspiking GABAergic interneurons. J Neurosci 29:7040-7052.

Petryniak MA, Potter GB, Rowitch DH, Rubenstein JL (2007) Dlx1 and Dlx2 control neuronal versus oligodendroglial cell fate acquisition in the developing forebrain. Neuron 55:417-433.

Pla R, Borrell V, Flames N, Marin O (2006) Layer acquisition by cortical GABAergic interneurons is independent of Reelin signaling. J Neurosci 26:6924-6934.

Pleasure SJ, Anderson S, Hevner R, Bagri A, Marin O, Lowenstein DH, Rubenstein JL (2000) Cell migration from the ganglionic eminences is required for the development of hippocampal GABAergic interneurons. Neuron 28:727-740.

Powell EM, Campbell DB, Stanwood GD, Davis C, Noebels JL, Levitt P (2003) Genetic disruption of cortical interneuron development causes region- and GABA cell type-specific deficits, epilepsy, and behavioral dysfunction. J Neurosci 23:622-631.

Robledo RF, Rajan L, Li X, Lufkin T (2002) The Dlx5 and Dlx6 homeobox genes are essential for craniofacial, axial, and appendicular skeletal development. Genes Dev 16:1089-1101.

Sohal VS, Zhang F, Yizhar O, Deisseroth K (2009) Parvalbumin neurons and gamma rhythms enhance cortical circuit performance. Nature 459:698-702.

Stumm RK, Zhou C, Ara T, Lazarini F, Dubois-Dalcq M, Nagasawa T, Hollt V, Schulz S (2003) CXCR4 regulates interneuron migration in the developing neocortex. J Neurosci 23:5123-5130.

Sussel L, Marin O, Kimura S, Rubenstein JL (1999) Loss of Nkx2.1 homeobox gene function results in a ventral to dorsal molecular respecification within the basal telencephalon: evidence for a transformation of the pallidum into the striatum. Development 126:3359-3370.

Tiveron MC, Cremer H (2008) CXCL12/CXCR4 signalling in neuronal cell migration. Curr Opin Neurobiol 18:237-244. 
Treiman DM (2001) GABAergic mechanisms in epilepsy. Epilepsia 42 [Suppl 3]:8-12.

Wonders CP, Anderson SA (2006) The origin and specification of cortical interneurons. Nat Rev Neurosci 7:687-696.

Xu Q, Cobos I, De La Cruz E, Rubenstein JL, Anderson SA (2004) Origins of cortical interneuron subtypes. J Neurosci 24:2612-2622.

Xu Q, Tam M, Anderson SA (2008) Fate mapping Nkx2.1-lineage cells in the mouse telencephalon. J Comp Neurol 506:16-29.

Yabut O, Renfro A, Niu S, Swann JW, Marin O, D’Arcangelo G (2007) Abnormal laminar position and dendrite development of interneurons in the reeler forebrain. Brain Res 1140:75-83.

Yun K, Fischman S, Johnson J, Hrabe de Angelis M, Weinmaster G, Ruben- stein JL (2002) Modulation of the notch signaling by Mash1 and Dlx1/2 regulates sequential specification and differentiation of progenitor cell types in the subcortical telencephalon. Development 129:5029-5040.

Zerucha T, Stuhmer T, Hatch G, Park BK, Long Q, Yu G, Gambarotta A, Schultz JR, Rubenstein JL, Ekker M (2000) A highly conserved enhancer in the $D l \times 5 / D l x 6$ intergenic region is the site of cross-regulatory interactions between $D l x$ genes in the embryonic forebrain. J Neurosci 20:709-721.

Zhao Y, Flandin P, Long JE, Cuesta MD, Westphal H, Rubenstein JL (2008) Distinct molecular pathways for development of telencephalic interneuron subtypes revealed through analysis of Lhx6 mutants. J Comp Neurol 510:79-99. 